\title{
CHROMOSOMAL BANDING PATTERNS OF TWO PARACENTRIC INVERSIONS
}

IN MICE

Murie1 T. Davisson and Thomas H. Roderick

The Jackson Laboratory, Bar Harbor, Maine 04609

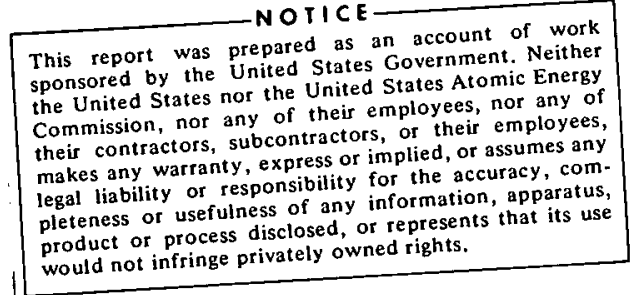




\section{DISCLAIMER}

This report was prepared as an account of work sponsored by an agency of the United States Government. Neither the United States Government nor any agency Thereof, nor any of their employees, makes any warranty, express or implied, or assumes any legal liability or responsibility for the accuracy, completeness, or usefulness of any information, apparatus, product, or process disclosed, or represents that its use would not infringe privately owned rights. Reference herein to any specific commercial product, process, or service by trade name, trademark, manufacturer, or otherwise does not necessarily constitute or imply its endorsement, recommendation, or favoring by the United States Government or any agency thereof. The views and opinions of authors expressed herein do not necessarily state or reflect those of the United States Government or any agency thereof. 


\section{DISCLAIMER}

Portions of this document may be illegible in electronic image products. Images are produced from the best available original document. 
Abstract. We have used banding techniques to study the chromosomes of mice heterozygous for two genetically defined paracentric inversions, In(1) $1 \mathrm{Rk}$ and In(2)5Rk. The banding patterns of the inversion-carrying chromosomes were altered as expected, and the relative lengths of the genetically and cytologically defined segments were comparable. 


\section{Introduction}

With the advent of techniques which bring out banding patterns in mammalian chromosomes, it has been possible to characteristizeand distinguish whole chromosomes and parts of chromosomes. We have used these techniques to study paracentric inversions in mice established by other cytological and genetic methods (Roderick and Hawes; 1970; Roderick, 1971). Our objective is to correlate evidence about inversions obtained through cytological and genetic methods. This paper is a report of our cytological demonstration of two inversions, $\operatorname{In}(1) 1 \mathrm{Rk}$ and In(2)5Rk, for which chromosome location was already known.

\section{Materials and Methods}

Nine males heterozygous for In(1)1Rk and five males heterozygous for In(2) $5 R k$ were studied. In each case heterozygosity for the inversion was established by the frequency of first meiotic anaphase bridges. Although modifications were necessary, the techniques for producing chromosomal banding patterns were based on published methods (Miller et al., 1971; Nesbitt and Francke, 1973; Wurster, 1972; Sun et a1., 1973). Standard air-dried bone marrow preparations were used for both methods. For fluorescent banding patterns fresh slides, were stained 10 min with a $50 \mu \mathrm{g} / \mathrm{ml}$ solution of quinacrine mustard dihydrochloride, rinsed 15 to 20 min in running tap water and coverslipped in tris maleate buffer ( $\mathrm{pH} 5.6$ ). Bands were obtained only after sufficient washing to remove all excess stain. Preparations for Giemsa banding were heat-dried 6-24 hr at $65^{\circ}$ and incubated 10 min in a potassium phosphate buffer $\left(\mathrm{pH} 6.8,56^{\circ} \mathrm{C}\right.$ ) just prior to 
enzyme treatment. Slides were either treated horizontally with a $0.025 \%$ solution of trypsin (Difco) or incubated in $0.05 \% \alpha$-chymotrypsin (Bovine pancreatic Type I, Sigma) at $37^{\circ}$ for $7 \mathrm{~min}$. Both enzymes were made up in $\mathrm{Ca}^{++}$- and $\mathrm{Mg}^{++}$-free Earle's saline. The slides were rinsed rapidly in two changes of the same saline and stained 5 min in $4 \%$ phosphate-buffered Giemsa. Photographs were made using Kodak High Contrast Copy film for Giemsa bands and Kodak Tri-X for quinacrine bands. Our designations of bands in this paper are those proposed by Nesbitt and Francke (1973).

The inverted segment In(1)1Rk can be seen in Figure 1. The characteristically bright central band (IE) is shifted toward the centromere and the negative band (1B) at the centromere end is widened, making inverted chromosome 1 superficially resemble chromosome 2 . The break points, of the inversion appear to be at the distal side of the most proximal negative band (1B) and inside the negative band (1F) just distal to the central bright band.

The definition of the inverted segment In(2)5Rk is not as striking (Figure 2). The characteristic negative band (2B) of chromosome 2 is not involved in the inverted segment. Distal to this band are two other major negative regions ( $2 \mathrm{D}$ and $2 \mathrm{~F}$ ). In the normal chromosome 2 the more distal (2F) is the wider of the two; in the inversion chromosome, the more proximal band (2D) is wider. This places the breakpoints within the two negative bands with a portion of the distal band contributing to the widening of the proximal one, or at the outer edges of each band or just beyond, with a complete substituion of the two bands. The latter seems 
more likely since In(2)5Rk is similar in bridge frequency and genetic length to In(1)1Rk and the longer segment is comparable in size to that seen in $\operatorname{In}(1) 1 R k$.

We made attempts to compare the relative physical lengths of each inversion with their relative genetic lengths. Composite diagrams for each inversion and its chromosome were made (by M.T.D.) based on several different photographs of each. The physical lengths of each inversion relative to its respective chromosome were calculated from the composite diagram: Then, independently (by T.H.R.) the best estimate of the genetic lengths of each inversion were compared with the estimated length of the chromosome. The genetic length of the chromosome was derived from the estimate of the total genetic length of the mouse, $1200 \mathrm{cM}$ (Searle et. al., 1970; Henderson and Edwards, 1968), multiplied by the percentages of the total physical length of each chromosome from actual chromosomal measurements (Committee, 1972). The genetic length of each inversion was derived from the maximum distance between those loci which do not recombine in the presence of the inversions (Roderick, Hawes, and Davisson, in preparation).

For In(1)IRk, the percentage of physical length was $42 \%$ and the percentage of genetic length was $37 \%$. For In(2)5Rk the respective percentages were $37 \%$ and $34 \%$. With the admitted possible errors involved in each estimate, these percentages are in good agreement, and provide evidence that the physical lengths and genetic lengths "are comparable at least over these segments of these chromosomes. 


\section{Discussion}

Pericentric inversions are presumed to exist when there is a shift in the relative lengths of arms of a specific chromosome without any alteration in the total length of any chromosome or change in chromosome number. Although many such alterations are probably pericentric inversions, there are other possible explanations (Duffey, 1972) which should encourage caution. In some cases in humans (for example Ferguson-Smith, 1967, and Wilson et al., 1970), further genetic and cytogenetic evidence has confirmed the presence of an inversion. Adding further, the techniques for banding chromosomes have been very important additional evidence (Evans et al., 1971; Hauksdóttir et:a1., 1972):

Our characterization of paracentric inversions in mice has utilized evidence from (1) anaphase bridge frequencies which are consistent for specific inversions and significantly above the normal background frequency, (2) the transmission of the specific frequencies in the normal genetic expectations, (3) the lack of high anaphase bridge frequencies in inversion-homozygotes, (4) the lack of recombination of genes within the inverted segment both with each other and with the inversion (Roderick,

- 1971; Roderick and Hawes, 1970, 1973).

The fact that these inversions can be detected cytologically using banding techniques, suggests using these techniques as a possible alternative means for screening for paracentric inversions both in man and in experimental mammals.

With the advent of techniques for showing banding patterns, it became possible to assign linkage groups of the mouse to specific chromosomes 
(Miller and Miller, 1972). Further application of these methods to mouse translocations has helped to establish the relative position with respect to the centromere of some individual genes and the location of certain genes near break-points of translocations (Miller et al., 1971, 1972, Francke and Nesbitt, 1971; Nesbitt and Francke, 1973). Inversions which can be characterized by these methods. will be additionally useful locating genes near breakpoints. Also they will be useful in relating whole segments of the genetic map to the physical dimensions of the chromosome. 


\section{Acknowledgments}

This study was supported by Contract AT(11-1)-3267 with the U.S . Atomic Energy Commission, by NIH Research Grant GM-19656 from the National Institute of General Medical Sciences, and by the Eloise and Richard Webber Foundation. The Jackson Laboratory is fully accredited by the American Association for Accreditation of Laboratory Animal Care. 


\section{References}

Committee on Standardized Genetic Nomenclature for Mice: Standard

karyotype of the mouse, Mus musculus. J. Hered. 63:69-72 (1972).

Duffey, P. A: : Chromosome variation in Peromyscus: A new mechanism.

Science 176:1333-1334 (1972).

Evans, H. J.; Buckton, K. E. and Sumner, A. T.: Cytological mapping of human chromosomes: Results obtained with quinacrine fluorescence and the acetic-saline-Giemsa technique. Chromosoma 35:310-325 (1971).

Ferguson-Smith, M. A.: Clinical cytogenetics, pp. 69-75. In J. F. Crow and J.V. Neel, eds.: Proceedings of the third international congress of human genetics (The Johns Hopkins Press, Baltimore 1967).

Francke, U. and Nesbitt, M.: Cattanach's translocation: Cytological characterization by quinacrine mustard staining. Proc. Nat. Acad. Sci. 68: 2918-2920 (1971).

Hauksdóttir, H.; Hallđorsson, S.; Jensson, 0.; Mikkelsen, M. and McDermott, A.: Pericentric inversion of chromosome no. 13 in a large family leading to duplication deficiency causing congenital malformations in three individuals. J. Med. Genet. 9:413-421 (1972). Henderson, S. A. and Edwards, R. G.: Chiasma frequency and maternal age in mammals. Nature, Lond. 218:22-28 (1968).

Miller, D. A.; Allerdice, P. W.; Kouri, R. E.; Dev, V. G.; Grewal, M. S.; Miller, 0. J. and Hutton, J. J.: Quinacrine fluorescent chromosome analysis of the Sne11 translocation in the mouse. Genetics 71 : 633-637 (1972). 
Miller, D. A.; Kouri, R. E.; Dev, V. G.; Grewal, M. S.; Hutton, J. J. . and Miller, 0. J.: Assignment of four linkage groups to chromosomes in Mus musculus and a cytogenetic method for locating their centromeric ends. Proc: Nat. Acad. Sci. 68:2699-2702 (1971).

Miller, D. A. and Miller, O.J.: Chromosome mapping in the mouse. Science 178:949-955 (1972).

Miller, O. J.; Miller, D. A.; Kouri, R. E.; Allerdice, P. W.; Dev, V. G.; Grewal, M. S. and Hutton; J. J.: Identification of the mouse karyotype by quinacrine fluorescence and tentative assignment of seven linkage groups. Proc. Nat. Acad. Sci. 68:1530-1533 (1971). Nesbitt, M. N. and Francke, U:: A system of nomenclature for band patterns

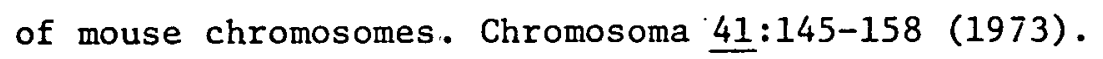

Roderick, T. H.: Producing and detecting paracentric chromosomal inversions in mice. Mut. Research. 11:59-69 (1971).

Roderick, T. H. and Hawes, N. L.: Two radiation-induced chromosomal inversions in mice (Mus musculus). Proc. Nat. Acad. Sci. 67: $961-967(1970)$

Roderick, T. H. and Hawes, N. L.: Nineteen paracentric chromosomal inversions in mice. Submitted to Genetics.

Searle, A. G.; Berry, R. J. and Beechey, C. V.: Cytogenetic radiosensitivity and chiasma frequency in wild-living male mice. Mut. Research $\underline{9}: 137-140(1970)$.

Sun, N. C.; Chu, E. H. Y. and Chang, C. C.: Staining method for the banding patterns of human mitotic chromosomes. Mammal. Chrom. Newsl. $\underline{14}: 26-28$ (1973). 
Wilson, M. G.; Towner, J. W.; Coffin, G. S. and Forsman, I.: Inherited pericentric inversion of chromosome no. 14. Amer. J. Human Genet. $\underline{22}: 679-690(1970)$.

Wurster, D. H.: Mouse chromosomes identified by trypsin-Giemsa (T-G) banding. Cytogenetics 11:379-387 (1972). 
F1g. 1. Multiple copies of Chromosomes 1 through 5 from animals heterozygous for In(1)1Rk. The inverted segment is designated by black bars.

Fig. 2. Multiple copies of Chromosome 1 through 5 from animals heterozygous for In(2)5Rk. The inverted segment is designated by bars. 


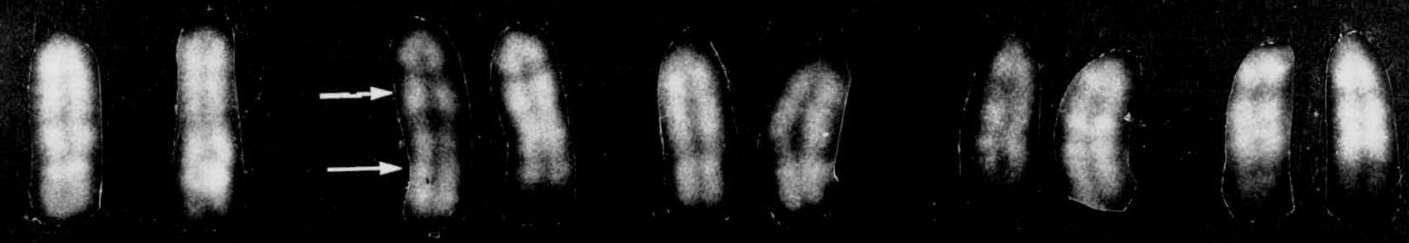

$$
\begin{aligned}
& \text { If } \\
& \begin{array}{lllll}
1 & 2 & 3 & 4 & 5
\end{array}
\end{aligned}
$$



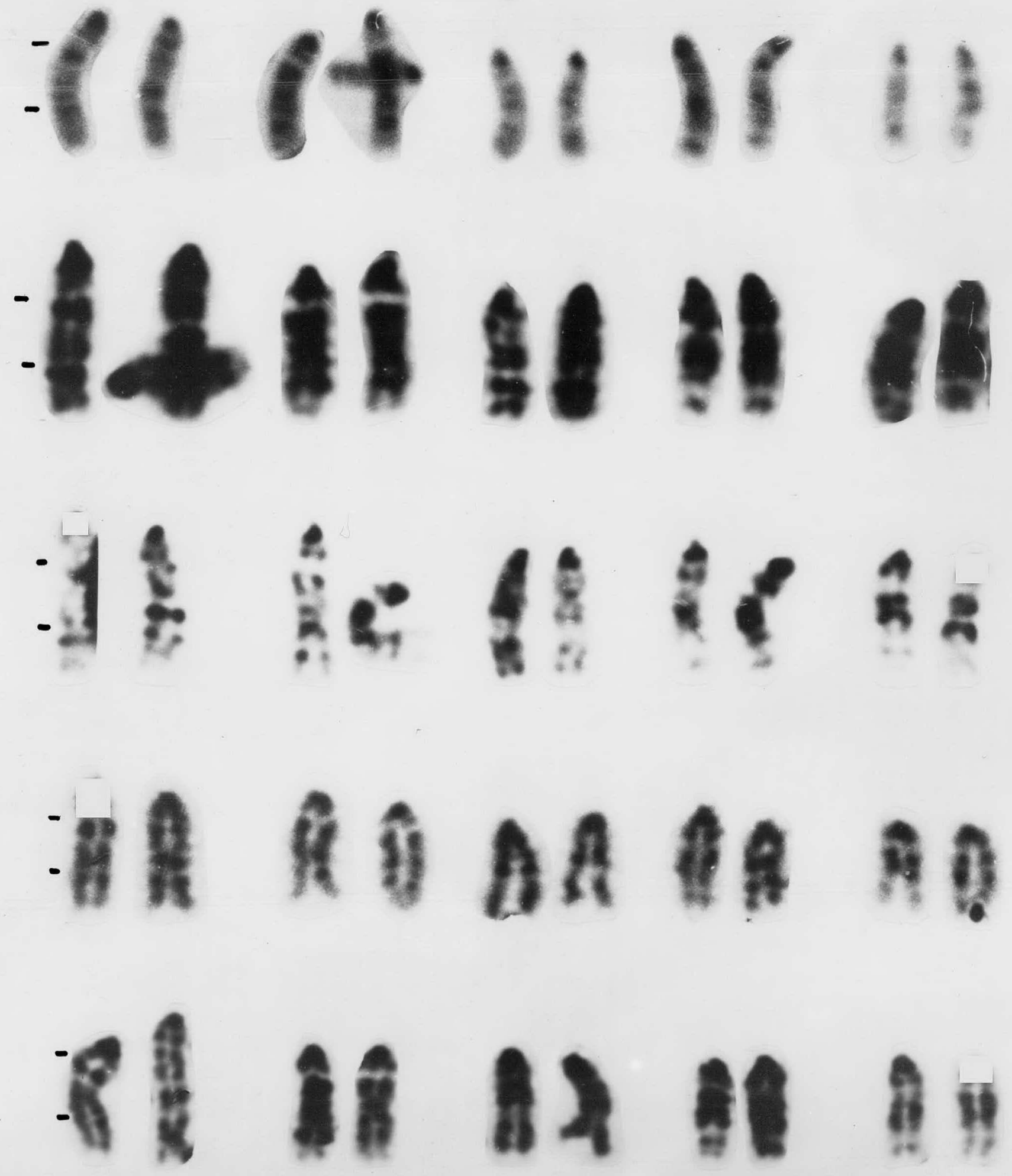